\title{
Impact of Laparoscopic Sleeve Gastrectomy on Gastric Emptying, Our Institutional Experience in Ain Shams University
}

\author{
Mohammed Hamed, MD, MRCS; ${ }^{1}$ Karim Fahmy, MD, MRCS; ${ }^{1}$ Samy Gamil Akhnoukh, MD; ${ }^{1}$ \\ Ahmed A Farag, MD2 \\ ${ }^{1}$ Department of Surgery, Faculty of Medicine, Ain Shams University \\ 2Department of Radio-Diagnosis, Faculty of Medicine, Ain Shams University
}

Background: Laparoscopic sleeve gastrectomy (LSG) is the most frequently performed procedure in the world and has overtaken the "gold standard" Roux-en-Y gastric bypass (RYGB) Obesity. The abstraction of the fundus is linked to physiological changes in gastric motility, as the gastric pacemaker is removed. Variable distance of antral resection from the pylorus is present in most cases. This is expected to provoke alterations in gastric emptying.

Aim of the Work: to assess the changes in gastric emptying after sleeve gastrectomy and determine the time needed for accommodation. Recommendation of prokinetic therapy was or not reached after this study.

Patients and methods: 30 morbidly obese patients who underwent LSG. 99mTc-sulfur colloid GE scintigraphy was performed on all patients pre and post-surgery. All operations were standardized regarding bougie size and distance of antral resection.

Results: The mean preoperative body mass index BMI is $44.65 \pm 4.26 \mathrm{~kg} / \mathrm{m} 2$ (range, $40-53$ ) and the mean preoperative body weight is $123.90 \pm 14.79 \mathrm{~kg}$ (range, 105 - 155). accelerated gastric emptying presented in 24 cases, delayed emptying in 3 cases and normal emptying in 3 cases. The mean preoperative percent of retention at 30 min was $71.83 \pm 14.83$ (range, $41.6-92$ ) decreased to $57.88 \pm 12.66$ (range, $38.1-80.1$ ) after 3 months, and a mean percent of retention at 30 min was $57.45 \pm 21.41$ (range, $18.7-85.2$ ) after 6 months.

Conclusion: Gastric emptying was significantly accelerated after sleeve gastrectomy with application of tight bougie (36 French size) and preservation of the antrum. There was strong correlation between delayed gastric emptying and appearance of postprandial symptoms which subsided after prokinetic therapy. However, further studies are required for comparison between tight and wide bougie as regards their effect on gastric emptying and weight regain.

Key words: Sleeve Gastrectomy, Gastric Emptying.

\begin{abstract}
Introduction
The sleeve gastrectomy is a restrictive intervention consisting of a vertical gastrectomy including the entire greater curvature of the stomach while leaving in place an approximately $100-\mathrm{ml}$ gastric tube along the lesser curvature. This intervention was initially proposed as the first part of a duodenal switch in patients whose body mass index was greater than $60 \mathrm{~kg} / \mathrm{m} 2$. Since then, these indications have developed and this intervention now enjoys certain favor on the part of bariatric surgery teams. ${ }^{1}$
\end{abstract}

Since 2007, LSG was characterized as more than a restrictive procedure. Evidence from literature showed hormonal changes after LSG. Long term decline in circulating ghrelin with enhanced postprandial release of the CCK, GLP-1 and PYY, the so-called gut peptides after LSG were pronounced in most of patients. ${ }^{2}$

Gastric motility reflects the endocrine nature of the stomach. Gastric motility acts as a mediator of hunger and satiety. Gastric emptying plays pivotal role in regulating appeite. The correlations between gastric accommodation and gastric peristalsis suggest that gastric motility may also affect the long-term regulation of body weight. However, there might be a consensus that gastric emptying is accelerated after LSG. There is still a debate concerning how much antrum should be resected in order to avoid interference with the gastric physiology and achieve optimum restrictive value. ${ }^{3}$

There is minimal evidence concerning how possibly these motility changes may be presented clinically as different sleeves are created owing to nonstandardized technique, different bougie size and variable distance of resection from pylorus. Thus, variable residual pouch volumes are produced. ${ }^{3}$

Radionuclide study on gastric motility popular and noninvasive. However, there is a lack of standardization of the test, including differences in the meals used, in patient positioning, and in the 
frequency and duration of imaging. differences in the quantitative data such as, half-time of emptying, rate of emptying, percentage of retention. ${ }^{4}$

In our study we tried to assess the impact of standardized LSG with bougie 36 and antral resection $6 \mathrm{~cm}$ from the pyloric ring on gastric motility and compared with preoperative results and to determine the time needed for accommodation.

\section{Patients and methodes \\ Patients}

30 morbidly obese patients who fulfilled the criteria for bariatric surgery were enrolled in a combined prospective study and had a retrospectively gathered outcome analysis at the department of surgery Ain-Shams University Hospitals from May 2015 to January 2017 with follow up till May 2018. A comprehensive assessment program was carefully structured so that a disciplined routine was followed in each patient. All patients were preoperatively and post-operatively evaluated. Ethical approval was taken from Ain Shams University ethical committee and written consent was taken from every patient after explanation of all details of the operation, advantages, disadvantages, diet habits after surgery, realistic expectations and with the possibility of conversion to open surgery and all the possible intra-operative, early and late postoperative complications. Surgeries were done by the same surgical team throughout the study.

\section{Inclusion criteria}

Age (18 - 60 year)

BMI $>40 \mathrm{~kg} / \mathrm{m} 2$ or BMI $>35 \mathrm{~kg} / \mathrm{m} 2$ with comorbidity suits to the indication of study.

\section{Exclusion criteria}

Morbid obese patients who were unfit for operation, history of previous abdominal surgery, any upper gastrointestinal endoscopic abnormalities ex. Reflux esophagitis, gastritis, and Psychiatric illness or on medications like narcotics.

\section{Methods}

All patients were subjected to full clinical history, examination, full blood tests. PAU/S and radioisotope scan.

\section{Operative Technique \\ We performed laparoscopic sleeve gastrectomy using five ports with the following steps:}

Patients were put in supine position and brought into a reverse Trendelenburg position with extended arms and the patients. The surgeon stood to the right side of the patient and the assistant to the left while the camera man stood between the patient's legs with the monitor placed above the patient's left shoulder. After $15 \mathrm{mmHg}$ pneumoperitoneum,
5 trocars were inserted with sizes of 5,10 and 12 and $15 \mathrm{~mm}$. $10 \mathrm{~mm}$ port above the umbilicus for camera, $5 \mathrm{~mm}$ epigastric port for liver retractor, 2 (5-12) ports one on the left midclavicular line just below the left rib arch and the other on the right midclavicular line $10 \mathrm{~cm}$ below the right rib arch, $2(5 \mathrm{~mm})$ ports one in the left anterior axillary line for the assistant. When the greater curvature was exposed, division of the gastroepiploic gastric branches, short gastric and posterior fundic vessels was done starting at $6 \mathrm{~cm}$ proximal to the pyloric ring. 36 French size bougie was introduced by the anesthesiologist to the stomach and the surgeon guides it along the lesser curvature into the pyloric channel and duodenal bulb. Through the right sided port (15 mm size), the first staple was applied (EndoGIA $3.8 \mathrm{~mm}$ of $60 \mathrm{~mm}$ length) at the greater curve $6 \mathrm{~cm}$ from the pyloric ring. Then, stapling was continued along the bougie. Instillation of saline with methylene blue was used to exclude leaks of the suture line. The resected specimen was removed through the $15 \mathrm{~mm}$ port of the right upper abdominal quadrant. tube drain was inserted in all cases.

\section{Post-operative management}

Patients received subcutaneous LMWH (clexane $\Re$ ) prophylactic dose $(0.5 \mathrm{mg} / \mathrm{kg}) 12$ hours after surgery after ensuring that there was no bleeding. IV 3rd generation cephalosporin together with analgesia and proton pump inhibitor (omeprazole $40 \mathrm{mg} / 24 \mathrm{hr}$.). An upper gastrointestinal contrast study (gastro-graffin study) was routinely performed in the second postoperative day.

\section{Post- operative Follow up}

\section{The follow up period of two years was carried} out on an outpatient basis:

1. Weekly visit for one month after discharge from the hospital.

2. Monthly visit till the end of the third month.

3. Visit every three months till the end of the follow up period.

\section{Surgical assessment of the following} characters for:

1. Diet regimen which is consequently classified into 4 stages

a. Stage 1: Water and sugar-free clear liquids ( 2 day after surgery / 1 day duration).

b. Stage 2: High-protein liquid supplements primarily (3 days after surgery or 24 hours after stage $1 / 4$ weeks' duration).

c. Stage 3: Soft-protein foods (4 weeks after surgery / 4 weeks duration).

d. Stage 4: Low-fat, low-sugar foods (Approximately 8 weeks after surgery / Lifelong duration).

2. Assess the Reduction of weight in 
proportional to time scale. $(3,6,9,12$ and 15 months).

3. Assessment of gastric emptying by radioisotope scan according to time scale (3rd month, 6th month).

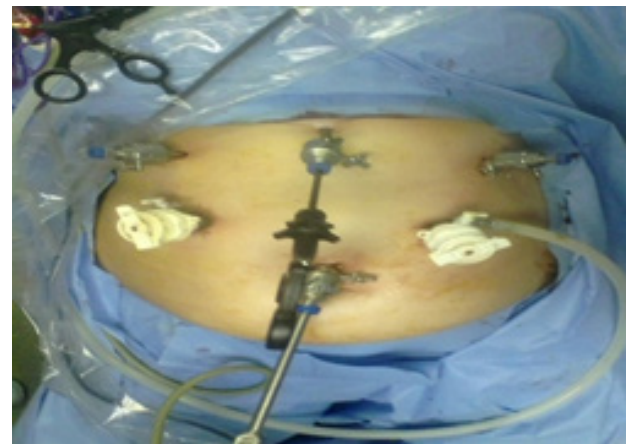

Fig 1: Trocars sites.

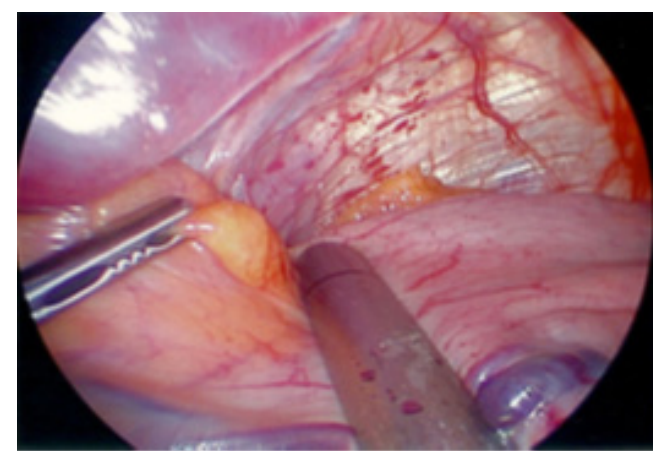

Fig 2: Application of stapler.

\section{Method of radio-isotope scan: \\ Patient preparation:}

1. Medications that alter gastric motility emptying of the stomach was withheld for 48-72 hours before isotopic studies some medications such as pain relievers and anticholinergic medications can decrease motility of the stomach. On the other side metoclopramide (Reglan) and erythromycin are associated with false positive results as they accentuate gastric motility

2. Patients were in fasting condition for $8 \mathrm{~h}$.

\section{Scanning technique and data a question:}

- The equipment used was a gamma camera system (Philips-Forte).Oral ingestion of the radiotracer sulfur colloid labeled with $99 \mathrm{mTc}$ in solid phase is used.

- The patient was asked to consume a meal of cooked egg white product (e.g. Egg-Beaters) labeled with $0.25-0.5 \mathrm{mCi}(9.25-18.5 \mathrm{MBq})$ $99 \mathrm{mTc}$ sulfur colloid, 2 slices of (toasted) white bread, jam or jelly, and $50 \mathrm{~mL}$ water.

- Repeated images were obtained in the same projections for 1 minute after 30 and 60 minutes.

- If the patient vomits at any time before the completion of the test, the results were invalid.

- The dose of radiation was (0.006-0.012 mSv) which was very trivial and doesn't pose any potential risk.

- A scanner (acting like a Geiger counter) was placed over the patient's stomach to monitor the amount of radioactivity in the stomach for several minutes after the test meal was eaten. The rate of gastric emptying was calculated.

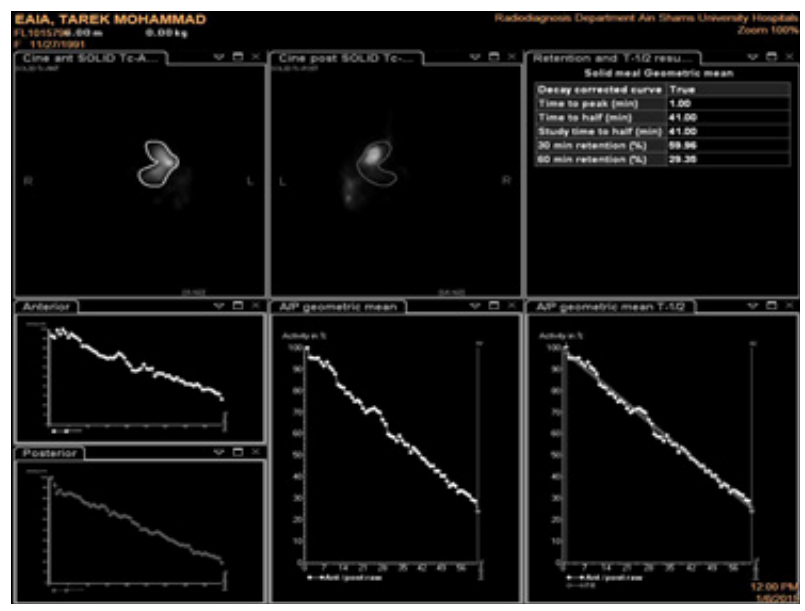

Fig 3: Curves of scan.

Data processing and interpretation:

- Data was processed using Bright View Jet Stream Philips software computer, Processing includes visual and quantification assessment with region of interest around the stomach and generating a time activity curve on which half time (T1/2) of emptying and percentage of retention were calculated.

- The following parameters were obtained for each patient:

$\diamond T 1 / 2$ : the time interval between the completion of the meal, and the point at which half of the meal (radioactivity counts) had left the stomach, was calculated from the raw data curve.

$\diamond 30 \mathrm{~min}$ and $60 \mathrm{~min}$ retention percentage.

\section{Data Management and Analysis:}

The collected data was revised, coded, tabulated and introduced to a PC using Statistical package for Social Science (SPSS 20). Data was presented and suitable analysis was done according to the type of data obtained for each parameter.

\section{Descriptive statistics:}

Mean, Standard deviation ( \pm SD) and range for numerical data.

\section{Analytical statistics:}

Paired t-test was used to assess the statistical significance of the difference between two means measured twice for the same study group

\section{P- value: level of significance \\ - $P>0.05$ : Non significant (NS). \\ - $\quad P<0.05$ : Significant (S). \\ - $\mathrm{P}<0.01$ : Highly significant (HS).}




\section{Results}

This study included thirty (30) patients 24 females and 6 males, with a mean age of $37.50 \pm 8.72$ years (range, 23-50) who underwent laparoscopic sleeve gastrectomy. The mean preoperative body mass index BMI was $44.65 \pm 4.26 \mathrm{~kg} / \mathrm{m} 2$ (range, 4053) and the mean preoperative body weight was $123.90 \pm 14.79 \mathrm{~kg}$ (range, 105-155).

Table 1: Demographic and preoperative data

\begin{tabular}{|c|c|c|c|c|c|c|c|}
\hline \multirow[b]{2}{*}{$\mathrm{Ht}$ (meter) } & \multicolumn{3}{|c|}{ Range } & \multirow{2}{*}{$\begin{array}{c}\text { Mean } \\
1.66\end{array}$} & & \multirow{2}{*}{$\begin{array}{l} \pm \\
\pm\end{array}$} & \multirow{2}{*}{$\begin{array}{c}\text { SD } \\
0.05\end{array}$} \\
\hline & 1.58 & - & 1.73 & & & & \\
\hline Wt. (Kg) preoperative & 105.0 & - & 155.0 & 123.90 & & \pm & 14.79 \\
\hline \multirow[t]{2}{*}{ BMI preoperative } & 40.0 & - & 53.0 & 44.65 & & \pm & 4.26 \\
\hline & & & $\mathbf{N}$ & & $\%$ & & \\
\hline \multicolumn{8}{|l|}{ Sex } \\
\hline Female & & & 24 & & 80.0 & & \\
\hline Male & & & 6 & & 20.0 & & \\
\hline \multicolumn{8}{|l|}{ Age } \\
\hline Range (year) & & & $23.0-50.0$ & & & & \\
\hline
\end{tabular}

30 patients underwent sleeve gastrectomy, all of them done laparoscopic, 2 cases were converted to open surgery, one due to leakage and other due to bleeding from short gastric vessel injury.

\section{Body BMI}

The mean preoperative body mass index was
$44.65 \pm 4.26$ (range, 40-53) decreased to $39.24 \pm$ 3.07 (range, $35.3-44.4$ ) after 3 months, a mean of $35.80 \pm 2.34$ (range, $32.3-38.6$ ) after 6 months, $33.38 \pm 2.20$ (range, $30.4-36.2$ ) after 9 months, $31.61 \pm 2.03$ (range, 28.7 - 35) after 12 months and a mean body mass index of $30.09 \pm 2.01$ (range, 27.5-34.4) after 15 months. (Table 2).

Table 2: Comparison between BMI at preoperative and at different points of measurement

\begin{tabular}{|c|c|c|c|c|c|c|c|c|}
\hline \multirow{2}{*}{ BMI } & \multirow{2}{*}{\multicolumn{3}{|c|}{ Range }} & \multirow{3}{*}{$\begin{array}{l}\text { Mean } \\
44.65\end{array}$} & \multirow{3}{*}{$\begin{array}{l} \pm \\
\pm\end{array}$} & \multirow{3}{*}{$\begin{array}{c}\text { SD } \\
4.26\end{array}$} & \multicolumn{2}{|c|}{ Paired t-test } \\
\hline & & & & & & & \multirow[t]{2}{*}{$\mathrm{t}$} & \multirow[t]{2}{*}{ P-value } \\
\hline Preoperative & 40.0 & . & 53.0 & & & & & \\
\hline 3 month & 35.3 & - & 44.4 & 39.24 & \pm & 3.07 & 15.409 & $<0.001$ \\
\hline 6 month & 32.3 & - & 38.6 & 35.80 & \pm & 2.34 & 16.085 & $<0.001$ \\
\hline 9 month & 30.4 & - & 36.2 & 33.38 & \pm & 2.20 & 20.013 & $<0.001$ \\
\hline 12 month & 28.7 & - & 35.0 & 31.61 & \pm & 2.03 & 20.303 & $<0.001$ \\
\hline 15 month & 27.5 & - & 34.4 & 30.09 & \pm & 2.01 & 20.853 & $<0.001$ \\
\hline
\end{tabular}

\section{Gastric emptying assessment:}

\section{A) T1/2:}

The mean preoperative $\mathrm{t} 1 / 2$ was $46.60 \pm 13.33$ (range, 25- 65) $\mathrm{min}$ decreased to $36.60 \pm 8.09$ (range, 27- 57) min after 3 months, and a mean t1/2 was $38.30 \pm 15.56$ (range, 12- 60) min after 6 months. Therefore, postoperative 6th month $\mathrm{t} 1 / 2$ was decreased in comparison to preoperative status but not significantly different in comparison to postoperative $3^{\text {rd }}$ month.

Table 3: Comparison between T1/2 at preoperative and at different points of measurement

\begin{tabular}{|c|c|c|c|c|c|c|c|c|}
\hline \multirow[b]{3}{*}{ Preoperative $t 1 / 2$} & \multirow{2}{*}{\multicolumn{3}{|c|}{ Range (min) }} & \multirow{3}{*}{$\begin{array}{l}\text { Mean } \\
46.60\end{array}$} & \multirow{3}{*}{$\begin{array}{l} \pm \\
\pm\end{array}$} & \multirow{3}{*}{$\begin{array}{c}\text { SD } \\
13.33\end{array}$} & \multicolumn{2}{|c|}{ Paired t-test } \\
\hline & & & & & & & \multirow[t]{2}{*}{$\mathbf{t}$} & \multirow[t]{2}{*}{ P-value } \\
\hline & 25.0 & - & 65.0 & & & & & \\
\hline Postoperative $3^{\text {rd }}$ month $\mathrm{t} 1 / 2$ & 27.0 & - & 57.0 & 36.60 & \pm & 8.09 & 3.254 & 0.003 \\
\hline Postoperative $6^{\text {th }}$ month $t 1 / 2$ & 12.0 & - & 60.0 & 38.30 & \pm & 15.56 & 1.880 & 0.070 \\
\hline
\end{tabular}


B) Percent of retention (30 $\mathrm{min}$ and $\mathbf{6 0} \mathrm{min}$ ): The mean preoperative percent of retention at 30 min was $71.83 \pm 14.83$ (range, 41.6-92) decreased to $57.88 \pm 12.66$ (range, $38.1-80.1$ ) after 3 months, and a mean percent of retention at 30 min was $57.45 \pm 21.41$ (range, 18.7-85.2) after 6 months. Therefore, postoperative 6th month percent of retention at 30 min was decreased in comparison to preoperative status but not significantly different in comparison to postoperative $3^{\text {rd }}$ month.
The mean preoperative percent of retention at 60 min was $28.00 \pm 15.76$ (range, 5.3-55.5) decreased to $21.24 \pm 7.46$ (range, 7.6-30) after 3 months, and a mean percent of retention at 60 min was 24.28 \pm 23.12 (range, 7.6-74.4) after 6 months. Therefore, postoperative 6th month percent of retention at $60 \mathrm{~min}$ was decreased in comparison to preoperative status but not significantly different in comparison to postoperative $3^{\text {rd }}$ month.

Table 4: Comparison between $30 \mathrm{~min}$ retention percent at preoperative and at different points of measurement

\begin{tabular}{|c|c|c|c|c|c|c|c|c|}
\hline \multirow[b]{3}{*}{ Preoperative 30 min retention } & \multirow{2}{*}{\multicolumn{3}{|c|}{ Range (\%) }} & \multirow{3}{*}{$\begin{array}{l}\text { Mean } \\
71.83\end{array}$} & \multirow{3}{*}{$\begin{array}{l} \pm \\
\pm\end{array}$} & \multirow{3}{*}{$\begin{array}{c}\text { SD } \\
14.83\end{array}$} & \multicolumn{2}{|c|}{ Paired t-test } \\
\hline & & & & & & & \multirow[t]{2}{*}{$\mathbf{t}$} & \multirow[t]{2}{*}{ P-value } \\
\hline & 41.6 & - & 92.0 & & & & & \\
\hline Postoperative 3 rd 30 min retention & 38.1 & - & 80.1 & 57.88 & \pm & 12.66 & 3.882 & $<0.001$ \\
\hline Postoperative 6 th 30 min retention & 18.7 & - & 85.2 & 57.45 & \pm & 21.41 & 2.538 & 0.017 \\
\hline
\end{tabular}

Table 5: Comparison between $60 \mathrm{~min}$ retention percent at preoperative and at different points of measurement

\begin{tabular}{|c|c|c|c|c|c|c|c|c|}
\hline \multirow[b]{3}{*}{ Preoperative 60 min retention } & \multirow{2}{*}{\multicolumn{3}{|c|}{ Range (\%) }} & \multirow{3}{*}{$\begin{array}{l}\text { Mean } \\
28.00\end{array}$} & \multirow{3}{*}{$\begin{array}{l} \pm \\
\pm\end{array}$} & \multirow{3}{*}{$\begin{array}{c}\text { SD } \\
15.76\end{array}$} & \multicolumn{2}{|c|}{ Paired t-test } \\
\hline & & & & & & & \multirow[t]{2}{*}{$\mathbf{t}$} & \multirow[t]{2}{*}{ P-value } \\
\hline & 5.3 & - & 55.5 & & & & & \\
\hline Postoperative 3 rd 60 min retention & 7.6 & - & 30.0 & 21.24 & \pm & 7.46 & 2.598 & 0.015 \\
\hline Postoperative 6 th 60 min retention & 7.6 & - & 74.4 & 24.28 & \pm & 23.12 & 0.903 & 0.374 \\
\hline
\end{tabular}

In our study it was discovered that accelerated gastric emptying presented in 24 cases, delayed emptying in 3 cases and normal emptying in 3 cases. (Table 6).

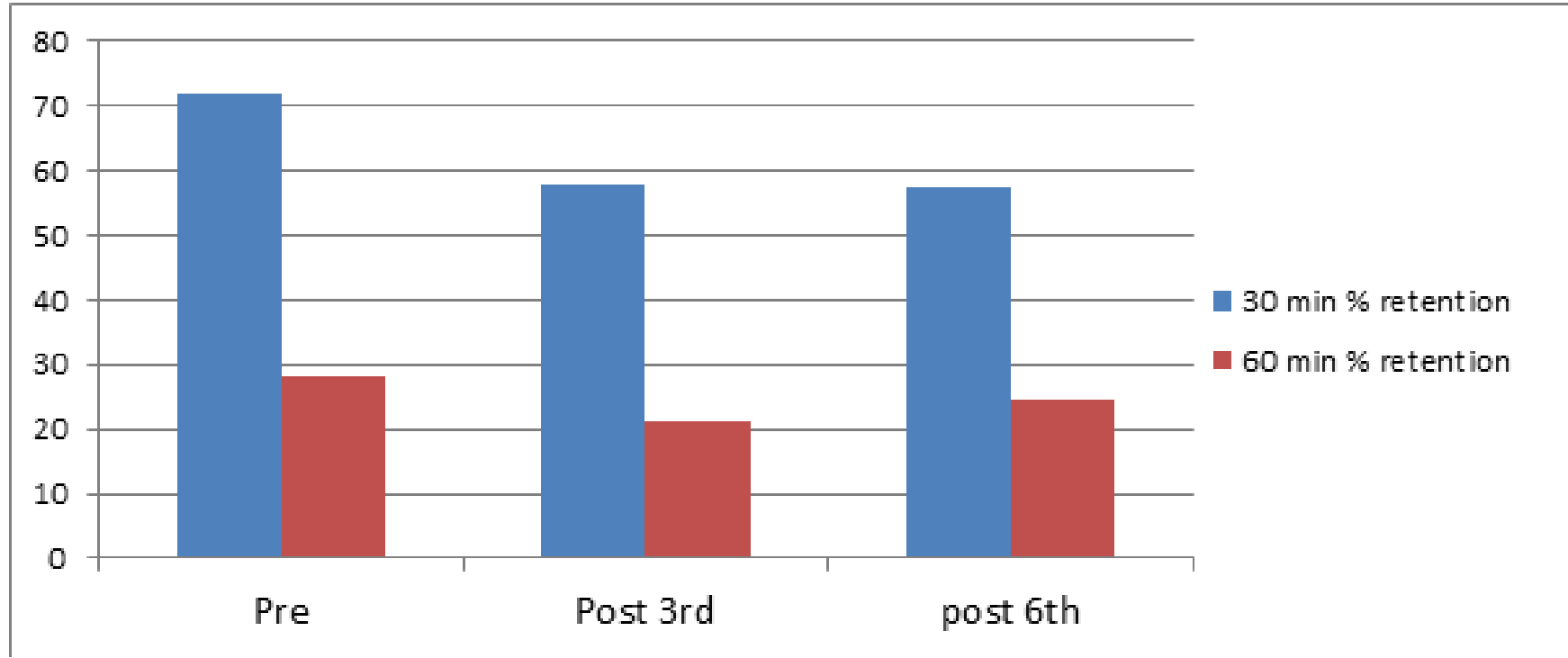

Fig 1: Comparison between 30 and 60 min retention percent at different points of measurement. 
Table 6: Effect of operation on gastric emptying

\begin{tabular}{ccc}
\hline Gastric empting & No of cases & Percent \\
\hline Accelerated & 24 & $80 \%$ \\
Delayed & 3 & $10 \%$ \\
Normal & 3 & $10 \%$ \\
\hline
\end{tabular}

\section{Post postoperative complications: (Table 7):}

One case $(3.33 \%)$ had leakage during methylene blue test due to misfiring of the $3^{\text {rd }}$ cartridge at the upper third of the stomach. This patient was converted to open surgery through upper midline incision and over sewing of the suture line was done. Patient discharged after 5 days. 2 cases $(6.67 \%)$ had bleeding: one from the suture line and clipping was done, the other from short gastric vessel and cannot be controlled laparoscopic, so converted to open surgery was done, one case was presented with leakage on the $2^{\text {nd }}$ day postoperatively. The patient presented with abdominal pain, fever and tachycardia on the sixth day. US was done and revealed turbid collection, pig tail was inserted and drainage was done. UGI endoscopy reveal small perforation in the gastroesophageal junction and mega stent was inserted. Patient improved and discharged after 10 days and stent was removed after 1 month. 3 cases (10\%) was presented with unsatisfactory weight loss. 3 cases $(10 \%)$ with delayed gastric emptying reported postprandial symptoms (nausea-dyspepsia- regurgitationepigastric discomfort.

Table 7: Complications of surgery

\begin{tabular}{ccc}
\hline & $\mathbf{N}$ & $\mathbf{\%}$ \\
\hline Intra operative Insult & & \\
Leakage & 1 & 3.33 \\
Bleeding & 2 & 6.67 \\
Early complications (< 1 month) & & \\
Mild gastritis & 4 & 13.33 \\
Leakage & 1 & 3.3 \\
Port site infection & 1 & 3.33 \\
Late complications (> 1 month) & & \\
Unsatisfactory WT loss & 3 & 10.00 \\
Postprandial symptoms & 3 & 10 \\
\hline
\end{tabular}

\section{Discussion}

Laparoscopic sleeve gastrectomy emerged as a restrictive bariatric procedure but its ability to reduce weight extends beyond that through many different mechanisms as hormonal and possible gastric emptying role. ${ }^{5}$

Laparoscopic sleeve gastrectomy has been practiced as a first stage surgical procedure for high risk, morbidly obese patients with a BMI of more than 50, however currently approved as sole bariatric procedure for patients with lower BMI. Evidence from literature showed marked improvement after sleeve gastrectomy with estimated weight loss from $52-82 \%$ at one year. ${ }^{5}$

The mean age of our participants was $37.50 \pm 8.72$ years (range, $23-50$ ), The mean preoperative body mass index BMI was $44.65 \pm 4.26 \mathrm{~kg} / \mathrm{m}^{2}$ (range, 40-53) and the mean preoperative body weight was $123.90 \pm 14.79 \mathrm{~kg}$ (range, 105-155). In the current study, there was statistically significant difference between the preoperative and postoperative weight, BMI at 3, 6, 9, 12 and 15 months following the operation.

In our study, the mean operative time was 96.90 min. there was two cases converted to open surgery $(6.66 \%)$. Conversion in one case was attributed to leakage during methylene blue test and the other due to bleeding from short gastric vessels. These results were comparable to Andreas et al. (2009) which included 15 patients, mean operative time was $147.6 \mathrm{~min}$. and the conversion rate was $(8.3 \%)^{6}$ and Rubin et al. (2008) which included 120 patients, mean operative time was 100 min and there was no conversion to open.?

The mean initial BMI for our patients was 44.65 $\mathrm{kg} / \mathrm{m}^{2}$, and last BMI postoperative decreased significantly to $30.09 \mathrm{~kg} / \mathrm{m}^{2}$, these results were comparable to Andreas et al. (2009) who reported BMI postoperatively was significantly reduced to $37.1 \mathrm{~kg} / \mathrm{m}^{2}$ from a preoperative value of 47 
$\mathrm{kg} / \mathrm{m}^{2}$. Rubin et al. (2008) who reported BMI postoperatively was significantly reduced to $34 \mathrm{~kg} /$ $\mathrm{m}^{2}$ from a preoperative value of $43 \mathrm{~kg} / \mathrm{m}^{2}$. This difference may be attributed to ethnic factors or the lower initial BMI of candidates.

Sioka E et al. (2018) in his meta-analysis found that 18 studies assessed stomach motility.12 studies were prospective studies, 4 studies were prospective randomized controlled studies and 2 were retrospective studies. The method of gastric emptying assessment was gastric scintigraphic studies were used in 14 in studies and (MRI) in one study, while one study used laparoscopic highresolution (HR) electrical mapping. All trials reported increased gastric emptying after LSG except for one. No correlation was observed between gastric emptying and postprandial symptoms in one study. ${ }^{2}$

\section{In our study gastric empting was accelerated after the operation (pyloric preserving technique) as follow:}

1. The mean preoperative $\mathrm{t} 1 / 2$ was $46.60 \pm 13.33$ min decreased to $36.60 \pm 8.09 \mathrm{~min}$ after 3 months, and a mean $\mathrm{t} 1 / 2$ was $38.30 \pm 15.56$ min after 6 months. These results were comparable to the study done by Bernstine et al. (2009) who found no difference in the half time value before and 3 months after LSG (respectively $62.4 \pm 19.8$ and $56.8 \pm 18.7 \mathrm{~min} ; \mathrm{p}=0.36$ ). This group explained that they did not remove any part of the antrum (stapling was done $7 \mathrm{~cm}$ from pylorus), and bougie size was $48 \mathrm{Fr}$ [8]. Melissas et al. (2007) also found a significantly accelerated gastric emptying in LSG patients, with gastric emptying half time that decreased from $86.5 \mathrm{~min}$ before LSG to $62.5 \mathrm{~min}$ at 6 months and 60.8 min at 24 months after LSG. Accelerated emptying in spite of pyloric preserving technique was explained as stomach division was done parallel to the $36 \mathrm{Fr}$ bougie and not $48 \mathrm{Fr}^{9}{ }^{9}$ Braghetto et al. (2009) found in a patient-control study that the half time of gastric emptying $\left(T^{1 / 2}\right)$ in patients were also significantly shorter compared to those in the control group $38.3 \pm 18.7$ min vs. $78 \pm 15.0$ min. 32 French bougie size was used, and stapling was done $4 \mathrm{~cm}$ from pylorus (partial antrectomy). ${ }^{10}$ Shah et al. (2010) found that gastric emptying half time values of a solid meal were also significantly shorter in the post SG group (52.8 \pm 13.5$)$ min than in the non SG (73.7 $\pm 29.0 \mathrm{~min})$ and control $(72.8 \pm 29.6$ min) groups. Partial antrectomy was done. ${ }^{11}$ Fallatah et al. (2013) (It was a comparative study between two groups with different techniques) found that in group A (pyloric preserving), the results were as follow, there was clear rapid antral emptying (average of 19 min), the mean time for gastric emptying was 20 minutes. Rapid emptying was explained due to application of tighter bougie $40 \mathrm{Fr}$. In group B (partial antrectomy), the gastric emptying study revealed much slower gastric emptying in comparison to group A, with an average of 91.5 min, and the mean gastric emptying time was 54 min. Slow emptying was explained because of affection of innervations of the pylorus.

2. The mean 30 min and 60 min retention percent was decreased (accelerated emptying) after surgery (Table 8).

Table 8: Showing 30 and 60 min retention percent results compared with other studies

\begin{tabular}{ccc}
\hline Our study & $\mathbf{3 0}$ min retention $\%$ & $\mathbf{6 0}$ min retention $\%$ \\
\hline Braghetto et al. (2009) & Preoperative: & $\begin{array}{c}\text { Preoperative: } 28.00 \pm 15.76 \\
\text { postoperative: } 21.24 \pm 7.46\end{array}$ \\
Bernstine et al. (2009) & $71.83 \pm 14.83$ postoperative: $57.88 \pm 12.66$ & Controls $(\mathrm{n}=18): 56 \pm 28$ \\
& - & Patients $(\mathrm{n}=20): 24.1 .3 \pm 0.20$ \\
& Preoperative: $73.10 \pm 13.04$ & Preoperative: $47.52 \pm 16.82$ \\
& Postoperative: $65.15 \pm 12.27$ & Postoperative: $38.36 \pm 17.89$ \\
\hline
\end{tabular}

\section{Theoretically, LSG affect emptying by several mechanisms:}

1. Removal of the fundus with its receptive and propulsive abilities.

2. Altered compliance and contractility of the narrow non distendable sleeve.

3. Removal of the gastric pacemaker area in the body of the stomach.

4. Hampering the action of the antral pump if part of the antrum was resected due affection of vagal innervation. ${ }^{12}$

So our results (accelerated gastric emptying) was explained due to: 
- Application of tight bougie.

- Complete removal of the fundus with its receptive ability.

- Removal of the pacemaker in the body which generates a slow wave basal rhythm.

- Creation of narrow gastric tube leading to increase intra gastric pressure.

- Pyloric antrum preservation with no affection of its neural supply.

SG may induce weight loss by reducing food intake, but in accelerated gastric emptying, delivery of nutrients to the small intestine early could activate small intestine satiety inducing chemoreceptors that could modify food ingestion periodicity with the subsequent consequences of weight regain. ${ }^{9}$ In our study we had 3 cases of unsatisfactory weight loss and their gastric emptying was accelerated.

From the symptomatology stand point, it was noticed that patients who had slow gastric emptying, had frequent complaints of nausea, vomiting and poor appetite. Treatment was done with prokinetic therapy like metoclopramide and domperidone with minimal resolution of symptoms but successfully managed with Ondansetron. In our study there were 3 cases with delayed gastric emptying complaining of postprandial symptoms and improved on prokinetics.

\section{Conclusion}

Gastric emptying was significantly accelerated after sleeve gastrectomy with application of tight bougie (36 French size) and preservation of the antrum. There was strong correlation between delayed gastric emptying and appearance of postprandial symptoms. However, further studies are required for comparison between tight and wide bougie as regards their effect on gastric emptying and weight regain. The limitations of the study include small sample size and the lack of long-term data beyond four years.

\section{Recommendation}

Each element that leads to acceleration of gastric emptying after sleeve gastrectomy should be studied alone.

Comparing different sizes of bougies on acceleration of gastric emptying after sleeve gastrectomy.

\section{Conflicts of interest}

There are no conflicts of interest.

\section{Refences}

1. Mognol P, Marmuse JP: Sleeve gastrectomy: a new approach to bariatric surgery. Journal De Chirurgie. 2007; 144 (4): 293-296.

2. Prinz $P$, Stengel A: Control of food intake by gastrointestinal peptides: Mechanisms of action and possible modulation in the treatment of obesity. Journal of Neurogastroenterology and Motility. 2017; 23(2): 180-196.

3. Sioka, et al: Impact of Laparoscopic Sleeve Gastrectomy on Gastrointestinal Motility. Gastroentrol Res Pract. 2018; (3): 120-126.

4. Berry R., Cheng L. K., Du P., et al: Patterns of abnormal gastric pacemaking after sleeve gastrectomy defined by laparoscopic highresolution electrical mapping. Obesity Surgery. 2017; 27(8): 1929-1937.

5. Fallatah B., AzizShehry A., Abdelsamad L., Zaid H., Hussain S., Jaber S: Comparison study of gastric emptying after performing sleeve gastrectomy with two different techniques. Journal of Surgery. 2013; 1(4): 53-56.

6. Andreas Kiriakopoulos, Christos Varounis, Dimitrios Tsakayannis, Dimitrios Linos: Laparoscopic sleeve gastrectomy in morbidly obese patients. Technique and short term results. Hormones. 2009; 8(2): 138-143.

7. Rubin $M$, Yehoshua RT: The role of the various factors contributing to the redfuction of food intake following sleeve gastrectomy. Proceedings of the $2^{\text {nd }}$ Annual International. Consensus Summit for Sleeve Gastrectomy ICSSG-2 Miami. 2009.

8. Bernstine H., Tzioni-Yehoshua R., Groshar D., et al: Gastric emptying is not affected by sleeve gastrectomy--scintigraphic evaluation of gastric emptying after sleeve gastrectomy without removal of the gastric antrum. Obesity Surgery. 2009; 19(3): 293-298.

9. Melissas J., Koukouraki S., Askoxylakis J., et al: Sleeve gastrectomy: a restrictive procedure? Obesity Surgery. 2007; 17(1): 57-62.

10. Braghetto I., Davanzo C., Korn O., et al: Scintigraphic evaluation of gastric emptying in obese patients submitted to sleeve gastrectomy compared to normal subjects. Obesity Surgery. 2009; 19(11): 1515-1521.

11. Shah S., Shah P., Todkar J., Gagner M., Sonar S., Solav S: Prospective controlled study of effect of laparoscopic sleeve gastrectomy on small bowel transit time and gastric emptying half-time in morbidly obese patients with type 2 diabetes mellitus. Surgery for Obesity and Related Diseases. 2010; 6(2): 152-157 Braghetto I., Davanzo C., Korn O., et al. Scintigraphic evaluation of gastric emptying in obese patients 
submitted to sleeve gastrectomy compared to normal subjects. Obesity Surgery. 2009; 19(11): 1515-1521.
12. Yehoshua R. T., Eidelman L. A., Stein M., et al: Laparoscopic sleeve gastrectomy-volume and pressure assessment. Obesity Surgery. 2008; 18(9): 1083-1088. 